\title{
CAMINHOS PARA A EDUCAÇÃO AMBIENTAL EM PARQUES
}

\author{
Camila P. Meireles ${ }^{1}$ \\ Douglas Camelo R. dos Santos ${ }^{2}$ \\ Douglas de S. Pimentel ${ }^{3}$
}

\section{RESUMO}

A Educação Ambiental (EA) no Brasil é exigida pela legislação, em caráter formal e nãoformal, mas nem sempre é desenvolvida plenamente no que se refere à continuidade e ao aprofundamento teórico-metodológico. Esses atributos são necessários ao processo de construção de valores sociais, conhecimentos, habilidades, atitudes e competências para a conservação ambiental. Considerando o Sistema Nacional de Unidades de Conservação, a EA está prevista em todas as categorias, inclusive como um dos objetivos principais dos parques. Desta forma, o presente trabalho visou a integrar alunos de Ensino Médio ao Parque Estadual da Serra da Tiririca - PESET (RJ), para promover a EA, divulgar a unidade de conservação e mudar a percepção dos estudantes sobre o Parque. A base metodológica foi a Pesquisa Qualitativa, com abordagem de Pesquisa-ação, através de atividades de EA no espaço formal de ensino e interpretação da natureza nas trilhas do PESET. A pesquisa foi desenvolvida de abril a novembro de 2008, com 28 alunos da $3^{\mathrm{a}}$ série do ensino médio de um colégio estadual de Niterói (RJ). Foram aplicados questionários antes e depois do projeto. Os alunos apresentaram conhecimento superficial sobre os conceitos de Meio Ambiente, Natureza, Educação Ambiental, Unidades de Conservação e Parque Natural. As atividades de EA possibilitaram o primeiro contato com o Parque e o vínculo necessário para desencadear maior participação e estímulo à formação de agentes multiplicadores de informações sobre a unidade de conservação. As estratégias de atuação apontadas nessa pesquisa são importantes para a inserção social dos Parques e formação de cidadãos críticos.

Palavras-chave: Educação Ambiental, Escola, Parque, Trilha Interpretativa.

\section{PATHWAYS TO ENVIRONMENTAL EDUCATION IN PARKS}

\section{ABSTRACT}

The Environmental Education (EE) in Brazil is required by law, in formal and non-formal character, but it is not fully developed in terms of continuity and theoretical-methodological deepening. These attributes are necessary to the process of building social values, knowledge, attitudes and skills for environmental conservation. Considering the National System of Conservation Units (SNUC), EE is foreseen in all categories, including as one of the main objectives of parks. In this way, the present work aimed at integrating secondary school students to the Serra da Tiririca State Park - PESET (RJ), to promote the EE in the conservation unit and change students' perception of the Park. The methodological basis was the Qualitative Research, with Action-Research approach, through EE activities in the formal space of teaching, and interpretation of nature in the PESET trails. The research was

\footnotetext{
1 Doutoranda do Programa de Pós Graduação em Biologia Marinha e Ambientes Costeiros da Universidade Federal Fluminense (UFF). Pesquisadora do Grupo de Estudos Interdisciplinares do Ambiente da Faculdade de Formação de Professores da Universidade do Estado do Rio de Janeiro (GEIA/FFP/UERJ). E-mail: camilameireles@id.uff.br

2 Pós-graduando em Bioenergia da Faculdade de Ciências e Tecnologia da Universidade Nova Lisboa. E-mail: douglascamelors@gmail.com

${ }^{3}$ Professor Adjunto da UERJ e UFF. Coordenador do GEIA (FFP/UERJ). E-mail: douglasgeia@gmail.com
} 
developed from April to November 2008, with 28 students from the 3rd grade of a high school in Niterói (RJ). Questionnaires were applied before and after the project. The students presented superficial knowledge about the concepts of Environment, Nature, Environmental Education, Conservation Units and Natural Park. EA activities enabled the first contact with the Park and the necessary link to trigger greater participation and stimulation to the formation of agents to multiply information about the conservation unit. The strategies of action indicated in this research are important for the social insertion of the Parks and training of critical citizens.

Key words: Environmental Education, School, Park, Interpretive Trail.

\section{INTRODUÇÃO}

No Brasil a Educação Ambiental (EA) é exigida pela Constituição Federal de 1988 e reafirmada pela lei 9.795/1999 e decreto 4.281/2002. Embora tenha evoluído conceitualmente no que se refere ao aumento da produção científica e à popularização de sua aplicação nos setores formal e não-formal, a EA ainda carece de continuidade e aprofundamento teóricometodológico para alcançar seus objetivos.

O Ministério do Meio Ambiente (MMA) se propõe, através do Sistema Nacional de Educação Ambiental (SisNEA), estruturar elementos do Programa Nacional (ProNEA) e da Política Nacional de Educação Ambiental (PNEA), para facilitar a coordenação interministerial para a gestão da EA. Dessa forma, a sua difusão pode fomentar pesquisas que apontem novas estratégias e indicadores. Porém, ainda hoje é comum ver esse termo reduzido ao ensino de ciências, associado com os aspectos ecológicos ou naturais das questões ambientais. Ações isoladas de um contexto social, político, cultural, histórico ou econômico são facilmente encontradas sob o título de EA. Cadei e colaboradores (2009, p. 471) acreditam que a EA é confundida com "questões relativas ao meio ambiente em aulas com ensino de ecologia, biologia, geografia, física ou química" porque foi implantada no Brasil em um "período de governo pouco democrático, em que certas questões sociais e políticas não podiam ser discutidas livremente", ocasionando seu desenvolvimento "numa vertente mais naturalista e fragmentada, voltada apenas para as grandes questões ecológicas (poluição, desmatamento, desertificação etc.)".

$\mathrm{Na}$ EA formal, isso pode ter influenciado a dificuldade dos educadores em desenvolver o tema transversal "Meio Ambiente", recomendado pelos Parâmetros Curriculares Nacionais (PCNs). Para Soares e colaboradores (2004), no cotidiano escolar este tema transversal

[...] tem se limitado a ações isoladas e/ou a entendimentos parcializados sobre a questão ambiental, orientados por uma visão excessivamente biologizada, dentro de uma vertente ecológico-preservacionista, e/ou fica restrita a eventos comemorativos (dia da árvore, dia do meio ambiente), ou ainda limitada à realização de algumas atividades práticas, denominadas extra-curriculares, eventuais (campanha do lixo, coleta para reciclagem, caminhadas ecológicas, visitas, plantio de hortas, etc.), sem a contextualização necessária e sem a internalização sobre o real entendimento da problemática ambiental no cotidiano das comunidades escolares (2004, p.9).

O tradicional ensino conteudista também é um obstáculo ao desenvolvimento da EA, visto que essa "constitui uma área de conhecimento eminentemente interdisciplinar, em razão dos diversos fatores interligados e necessários ao diagnóstico e à intervenção que pressupõe" 
(CASTRO; BAETA, 2005, p. 99), visando "superar a fragmentação do conhecimento" (COIMBRA, 2005, p.117). Assim, os educadores precisam buscar novos caminhos para o desenvolvimento da EA. Segundo Collere (2005), o desenvolvimento do ensino por meio de projetos é uma das melhores formas de atingir a interdisciplinaridade no processo educativo, pois eles possibilitam variadas atividades de reflexão dos conteúdos escolares em interação com as várias áreas do conhecimento.

Nos PCNs, a relação da escola com o ambiente em que está inserida também é considerada como um ponto importante, pois essa instituição social exerce intervenção na realidade e deve estar conectada com as questões mais amplas da sociedade e com os movimentos de defesa da qualidade do ambiente, incorporando-os às suas práticas (BRASIL, 1998). Além disso, afirma ser "desejável a saída dos alunos para passeios e visitas a locais de interesse dos trabalhos em Educação Ambiental", sendo "importante que se faça um levantamento de locais como parques, empresas, unidades de conservação, serviços públicos, lugares históricos e centros culturais, e se estabeleça um contato para fins educativos" (BRASIL, 1998, p.192).

No caso das Unidades de Conservação (UC), a EA se mostra de extrema importância nas suas várias finalidades. Segundo a Lei n n $^{9.985}$, de 18 de julho de 2000 (BRASIL, 2000), do Sistema Nacional de Unidades de Conservação (SNUC), as UC de todas as categorias devem servir como espaços para a realização de atividades de Educação ou Interpretação Ambiental, idealizadas de forma a conectar os visitantes com o lugar, criar maior consciência, compreensão e apreciação dos recursos naturais e culturais protegidos, provocar mudanças de comportamento, atrair e envolver as pessoas nas tarefas de conservação, aumentar a satisfação dos usuários, criar uma imagem positiva da UC e da instituição responsável e tornar a visitação mais planejada e menos impactante (VASCONCELLOS, 2006). Nesse sentido, a EA assume diferentes dimensões para a gestão dos parques, tanto no que concerne a preservação da biodiversidade, quanto à sustentabilidade das suas formas específicas de uso público.

As UC assumem sua função educativa ao oferecer o "contato direto com ambientes naturais, ricos em oportunidades e experiências sensoriais e afetivas, com desafios cognitivos" (VASCONCELLOS, 2006, p.21). Nesse sentido, Silva e Neto (2007) destacam o caráter deficitário da EA na educação formal e apontam que as UC podem suprir essa lacuna.

As atividades educativas em UC também têm o potencial de viabilizar práticas que promovam uma visão crítica sobre as relações entre sociedade e ambiente (PIMENTEL; MAGRO, 2011). Pimentel e Magro (2012 a e b) ressaltam ainda, que o estímulo à reflexão crítica tem o poder de sensibilizar as pessoas para diferentes questões ambientais por intermédio da aquisição de conhecimentos e habilidades; de promover uma análise crítica sobre as relações socioambientais e as dicotomias entre natureza e cultura; bem como de inserir as UC na realidade social.

Uma estratégia comumente empregada em UC por guias e educadores ambientais, e que pode promover uma ponte entre a área protegida e a escola, são as Trilhas Interpretativas. As Trilhas Interpretativas têm origem na interpretação ambiental, a qual surgiu no contexto 
dos parques nacionais americanos e foi definida por Freeman Tilden em uma publicação clássica de 1957, Interpreting Our Heritage, como (TILDEN, 1977, p. 8):

[...] atividade educativa que aspira revelar os significados e as relações existentes no ambiente, por meio de objetos originais, através de experimentos de primeira mão e meios ilustrativos, em vez de simplesmente comunicar a informação literal.

Considerando que a conservação da natureza não depende apenas dos aspectos ecológicos ou naturais, mas principalmente das relações socioambientais, o presente trabalho apresenta caminhos para o desenvolvimento da EA unindo Escola e Parque. As atividades visaram integrar alunos de Ensino Médio da rede pública de Niterói ao Parque Estadual da Serra da Tiririca (PESET), aliando conhecimento, reflexão, desafios, afetividade, curiosidade, imaginação e noção de pertencimento, para cumprir os objetivos da Educação Ambiental e da Conservação da Natureza. Bem como, promover uma mudança de percepção dos alunos sobre o PESET, apontando estratégias, identificando indicadores deste processo e gerando produtos que possibilitem a divulgação do Parque, a difusão da EA e a valorização das pesquisas e descobertas dos alunos.

\section{MATERIAL E MÉTODOS}

\section{Área de estudo - O Parque Estadual da Serra da Tiririca}

O Parque Estadual da Serra da Tiririca (Figura 1) - PESET - situa-se em cadeia montanhosa perpendicular à costa, na divisa dos municípios de Niterói e Maricá. Foi promulgado em 29/11/91 e é administrado pelo Instituto Estadual do Ambiente (INEA), órgão vinculado ao Governo do Estado do Rio de Janeiro. Sua área atual é de aproximadamente 3.493 hectares. Seu perímetro definitivo foi estabelecido na Lei Estadual $n^{\circ} 5.079$, de 3 de setembro de 2007, e retificado em abril de 2011. Outras ampliações ocorreram em 2008 (Decreto $\mathrm{n}^{\mathrm{o}}$ 41.266, de 16 de abril de 2008) e 2012 (Decreto Estadual $\mathrm{n}^{\circ}$ 43.913, de 29 de outubro de 2012), porém ainda apresenta áreas em disputa, principalmente no entorno da Lagoa de Itaipu (INEA, 2019). Historicamente é uma região de grande relevância, pois faz parte dos estudos do naturalista Charles Darwin, que esteve na Serra da Tiririca em sua passagem pelo Rio em 1832 (SELLES; ABREU, 2002). Sofre com as pressões imobiliárias, presença de espécies invasoras, visitação crescente, entre outros.

Figura 1: Mapa com os limites do PESET (INEA, 2019). 


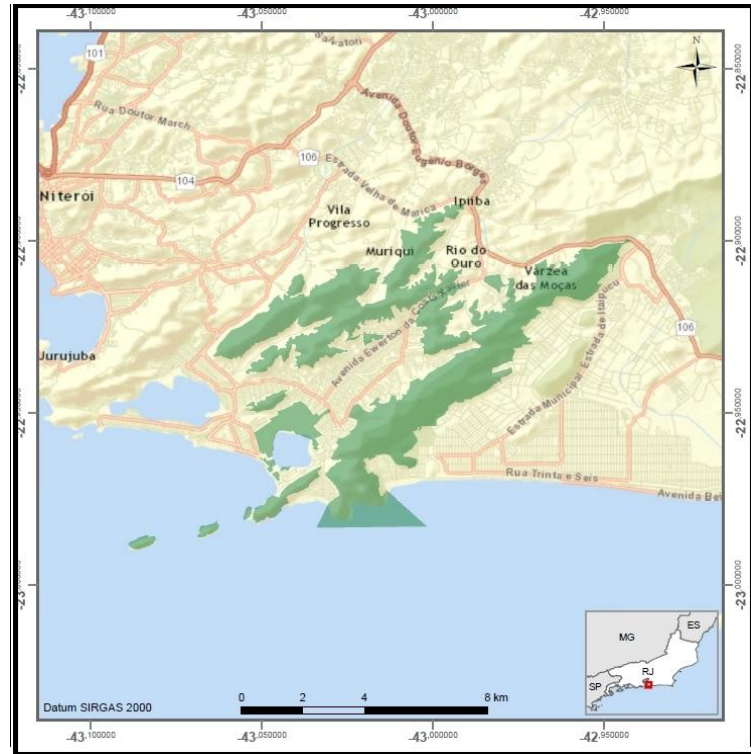

\section{Abordagem Teórica}

A pesquisa foi orientada segundo o conceito de Educação Ambiental da lei 9795 da Política Nacional de EA, que a define, nos seus artigos $1^{\circ}$ e $2^{\circ}$, como:

Processos por meio dos quais o indivíduo e a coletividade constroem valores sociais, conhecimentos, habilidades, atitudes e competências voltadas para a conservação do meio ambiente, bem do uso comum do povo, essencial à qualidade de vida e sua sustentabilidade. A EA é um componente essencial e permanente da educação nacional, devendo estar presente, de forma articulada, em todos os níveis e modalidades do processo educativo, em caráter formal e não formal (BRASIL, 1999).

A base metodológica foi a Pesquisa Qualitativa (TRIVIÑOS, 1987). Abordagens de Pesquisa-ação foram adotadas para possibilitar a investigação do processo de ensino e aprendizagem e gerar uma reflexão-ação construída coletivamente (FRANCO, 2005).

A coleta de dados foi realizada através de aplicação de questionário diagnóstico, com perguntas abertas e fechadas, atividades na escola e Trilhas Interpretativas no Parque. Os dados foram processados através de Análise de Conteúdo (BARDIN, 1977), na qual as respostas dos questionários foram categorizadas (Quadro 1), considerando frases ou falas como ideias do núcleo dos sentidos. Em alguns casos, o mesmo aluno apresentou falas diferentes, sendo representado em mais de uma categoria. As categorias foram criadas após leitura flutuante das respostas em ambas as etapas do questionário, no início e no final do projeto.

Quadro 1: Categorias das respostas analisadas.

\begin{tabular}{|l|l|}
\hline Categorias (visões) & Ideia do núcleo dos sentidos (conceituações) \\
\hline Socioambiental & O homem ou a sociedade estão inseridos. \\
\hline Ecológica/ Naturalista & Ecológica (habitat, população, comunidade, ecossistema) e/ou naturalista \\
\hline Conscientização Ambiental & Conscientização ambiental. Forma de adquirir conhecimento. \\
\hline Conservacionista & Conservação (manejo do uso humano do meio). \\
\hline Natureza Danificada & Natureza modificada pela ação destrutiva do homem. \\
\hline Romântica & Romântica, emotiva, otimista, sentimental. \\
\hline Natureza Intocada & Natureza preservada, intocada, sem influência do homem. \\
\hline
\end{tabular}




\begin{tabular}{|l|l|}
\hline Utilitária & Uso dos recursos naturais em benefício do homem. \\
\hline Problema Ambiental & Conscientização para os problemas ambientais. \\
\hline Paisagem & Beleza cênica, paisagem. Senso estético. \\
\hline Institucional & Instituição (IBAMA, escolas). \\
\hline Restritiva ou Proibitiva & Lugar demarcado, com proibições e fiscalização. \\
\hline Abrangente & Vários aspectos de forma integrada. \\
\hline Generalizante ou Tautológica & Generalizante, superficial (tudo, nada) ou tautológica (sem sentido). \\
\hline
\end{tabular}

\section{Abordagem Prática}

A pesquisa foi realizada com 28 estudantes (18 alunas e 10 alunos) entre 16 e 20 anos de idade, do $3^{\circ}$ ano do Ensino Médio do Colégio Estadual Paulo Assis Ribeiro, localizado no bairro de Pendotiba, em Niterói (RJ). As atividades na escola foram desenvolvidas de abril a novembro de 2008, semanalmente, durante os dois tempos de aula da disciplina "Projeto", cedidas pelo professor de biologia Vitor Pombo, que acompanhou todo o processo (Quadro 2). A equipe foi composta por uma educadora ambiental, um estagiário e um professor orientador, integrantes do Grupo de Estudos Interdisciplinares do Ambiente da Universidade Federal do Rio de Janeiro.

Quadro 2: principais atividades realizadas

\begin{tabular}{|l|}
\hline \multicolumn{1}{|c|}{ Atividades } \\
\hline Aplicação de questionários e elaboração de pergunta sobre o PESET \\
\hline Dinâmica de "Batata-quente" sobre respostas do questionário \\
\hline Montagem de cartazes com imagens e definições sobre Meio Ambiente \\
\hline Leitura e interpretação de texto sobre Meio Ambiente \\
\hline Exibição de vídeo com discurso feito durante o evento Eco-92 \\
\hline Visita ao Meio Ambiente escolar \\
\hline Trilha Interpretativa - Enseada do Bananal (PESET) \\
\hline "Bate Papo" sobre a visita ao PESET e resolução da primeira lista de perguntas \\
\hline Exibição das fotos do PESET e elaboração de nova lista de perguntas \\
\hline Trilha Interpretativa - Morro das Andorinhas (PESET) \\
\hline Leitura e Interpretação do texto "O Manejo de Parques e a população" \\
\hline "Jogos Olímpicos do PESET" \\
\hline Resolução da segunda lista de perguntas sobre o PESET e exibição das fotos \\
\hline Apresentação de Palestra \\
\hline Apresentação de Painel e elaboração de depoimentos \\
\hline Escolha e elaboração do produto final realizado pelos alunos \\
\hline Elaboração da exposição \\
\hline Aplicação da segunda etapa do questionário e avaliação pessoal do Projeto \\
\hline
\end{tabular}

\section{RESULTADOS E DISCUSSÃO}

A primeira etapa da pesquisa consistiu em gerar um diagnóstico com os estudantes sobre o tema "Parque Estadual da Serra da Tiririca", antes da realização das atividades. Assim, foi possível identificar que tipo de conhecimento prévio já apresentavam sobre a temática. A análise dos questionários diagnósticos e da lista de perguntas elaboradas pelos alunos sobre o PESET indicou desconhecimento da unidade de conservação, embora esta esteja localizada a poucos quilômetros da escola. Desta forma, uma maquete da cidade de Niterói presente na escola foi utilizada para apresentar a região da Serra da Tiririca e a 
localização do Parque. Na atividade seguinte, a dinâmica de "Batata-quente" foi realizada como ferramenta lúdica para promover um debate sobre algumas questões socioambientais abordadas nas respostas do questionário diagnóstico, como por exemplo o problema do lixo.

A partir daí, foi trabalhado o conceito de "Meio Ambiente". Na atividade de produção de cartazes para definição do termo, as imagens usadas revelaram uma confusão com o conceito de "Natureza, fato também observado por Fritzsons e Mantovani (2004). Imagens com seres humanos ou sociedade raramente foram inseridos. Assim, a "(des)construção" do conceito foi desenvolvida através de interpretação de textos, vídeos e visita ao próprio ambiente escolar. Para isso, foi considerada a definição dos PCNs (BRASIL, 1998, p. 233):

O termo "meio ambiente" tem sido utilizado para indicar um "espaço" (com seus
componentes bióticos e abióticos e suas interações) em que um ser vive e se
desenvolve, trocando energia e interagindo com ele, sendo transformado e
transformando-o. No caso dos seres humanos, ao espaço físico e biológico soma-se
o "espaço" sociocultural. Interagindo com os elementos do seu ambiente, a
humanidade provoca tipos de modificação que se transformam com o passar da
história. E, ao transformar o ambiente, os seres humanos também mudam sua
própria visão a respeito da natureza e do meio em que vivem.

Após o reconhecimento do espaço escolar como componente do "Meio Ambiente", os alunos foram conduzidos em uma primeira visita ao PESET, realizada em junho de 2008, com 14 alunos, na Trilha Interpretativa da Enseada do Bananal (PIMENTEL et. al, 2017), localizada na subsede do Parque, em Itacoatiara. Os estudantes participaram de um briefing que abordou a conduta consciente em unidades de conservação e a história da passagem do naturalista inglês Charles Darwin pela região em 1832 (SELLES; ABREU, 2002). A equipe provocou uma reflexão sobre os instrumentos simples que Darwin teria utilizado para seus estudos na época e, para incentivar essa estratégia de pesquisa, entregou aos estudantes um bloco para anotação, chamado de "caderno naturalista". No entanto, os alunos apresentaram dificuldade em registrar suas impressões durante a caminhada e alguns anotaram a fala dos professores e condutores, reproduzindo um hábito do ensino conteudista, baseado em aulas expositivas. Por isso, posteriormente, em sala de aula, foi aplicado um roteiro de perguntas sobre a visita. A maioria destacou a beleza do lugar (12 de 14 alunos) e alguns depoimentos chamaram a atenção por destacarem a superação do medo e da dificuldade, o sentimento de liberdade e a vontade de voltar ao Parque. Vasconcellos (2006) compara a Trilha Interpretativa à educação ao ar livre, com forte ligação a subjetividades e emoção.

Em sala de aula os alunos também responderam à primeira lista de perguntas que haviam feito e elaboraram uma nova. As perguntas elaboradas antes do primeiro contato buscaram caracterizar o Parque (localização, definição, função, etc.), enquanto a nova apresentava curiosidades típicas de quem visitou o local. Vasconcellos ressalta que "a interpretação ambiental deve incluir informação, mas tem que ir muito além, provocando a curiosidade, a vontade de saber mais, revelando o significado por trás das aparências" (2006, p.25). Os alunos que não compareceram à primeira visita conheceram o Parque através de uma exibição de fotos realizada em sala com depoimentos dos participantes.

Em setembro de 2008 foi realizada a segunda visita ao PESET, com 12 alunos, na Trilha Interpretativa do Morro das Andorinhas (PIMENTEL et. al, 2017), localizada em 
Itaipu. Dentre esses, 10 citaram a presença do ser humano em seus depoimentos sobre o local, o que era esperado visto que a trilha percorrida apresenta habitações de pescadores tradicionais da região. A situação dos moradores foi discutida, considerando o conceito de população tradicional e os seus direitos, bem como a visão mais restritiva definida no SNUC para parques. Assim, o texto "O Manejo de Parques e a população" (PRIMACK; RODRIGUES, 2001) foi comparado à situação do Morro das Andorinhas.

$\mathrm{Na}$ dinâmica "Jogos Olímpicos do PESET", inspirada nos Jogos Olímpicos que ocorriam na ocasião, a turma se dividiu em grupos para elaborar questionamentos e testar seus conhecimentos sobre o Parque. A vivência no Parque e a competição gerada pelo jogo estimularam a produção de perguntas mais aprofundadas (Quadro 3).

Quadro 3: Exemplo de perguntas e respostas elaboradas pelos alunos:

\begin{tabular}{|c|c|}
\hline Perguntas & Respostas \\
\hline $\begin{array}{l}\text { Ao olhar de um dos mirantes do Morro das } \\
\text { Andorinhas podemos avistar um elemento que } \\
\text { chama nossa atenção e que não deveria pertencer } \\
\text { ao ambiente natural. Qual é o elemento em } \\
\text { questão? }\end{array}$ & $\begin{array}{l}\text { A intervenção do homem na natureza, construindo } \\
\text { mansões para seu maior conforto sem } \\
\text { conscientização. Com esta atitude está degradando } \\
\text { a natureza ". }\end{array}$ \\
\hline $\begin{array}{l}\text { Por que o número de nascentes e córregos vem } \\
\text { sofrendo regressão? }\end{array}$ & Devido à destruição da cobertura vegetal \\
\hline $\begin{array}{l}\text { Por que as atividades mineradoras na área do } \\
\text { PESET eram ilegais? }\end{array}$ & $\begin{array}{l}\text { Porque os empreendimentos exerciam uma } \\
\text { atividade econômica altamente impactante e porque } \\
\text { se situavam em área de Mata Atlântica. Assim, } \\
\text { intensificaram-se as pressões por parte de } \\
\text { ambientalistas sobre os empreendimentos }\end{array}$ \\
\hline $\begin{array}{l}\text { Qual o objetivo de Unidade de Proteção Integral } \\
\text { como o PESET? }\end{array}$ & $\begin{array}{l}\text { A Unidade de Proteção Integral tem como seu } \\
\text { maior objetivo preservar o ambiente natural da } \\
\text { Serra da Tiririca, admitindo-se unicamente o uso } \\
\text { indireto dos seus recursos naturais }\end{array}$ \\
\hline
\end{tabular}

Pimentel e Magro (2012b) reafirmam a importância da EA nessas áreas protegidas, pois suas práticas socialmente referenciadas podem estimular uma visão crítica e interligada as atribuições básicas dos parques. Bensusan (2006) destaca que conservar a biodiversidade ignorando o cenário político e social mais amplo é pouco eficaz, visto que sem levar em conta os problemas e direitos das populações locais, criam-se conflitos que podem ameaçar a integridade da UC. Ao todo, 19 alunos visitaram o PESET, sendo que sete foram a todas as trilhas. Dos 25 alunos que fizeram a avaliação pessoal do Projeto, todos os que visitaram o Parque citaram que a trilha interpretativa foi a atividade que eles mais gostaram. Para a atividade final, os alunos decidiram produzir um painel sobre o projeto para apresentar em festa de final de ano da escola.

Embora a formação acadêmica da equipe fosse biologia, as questões sociohistóricas foram as mais frequentes nos debates em sala de aula. A especulação imobiliária crescente pressionando a redução dos limites da UC, assim como a iniciativa popular presente em toda a história do PESET e a importância da gestão participativa, foram os temas mais recorrentes. 
No questionário diagnóstico os alunos declararam obter informações sobre as questões ambientais primordialmente pela TV e pela escola. Apenas seis já haviam participado de alguma atividade de EA. Entre as atividades citadas estavam: plantio de mudas, curso, palestra, visita ao Parque da Cidade (Niterói/ RJ) e coleta de lixo. Somente três alunos sabiam que Niterói tem Unidades de Conservação, sendo que dois citaram o Parque da Cidade e somente um mencionou o PESET. Nenhum aluno conhecia o PESET pessoalmente, oito conheciam a Serra da Tiririca, mas só quatro sabiam que era um Parque Estadual.

$\mathrm{Na}$ primeira etapa de aplicação do questionário, em geral, os alunos apresentaram noções superficiais dos conceitos de Natureza, Meio Ambiente, EA, UC e Parque Natural. No entanto, apresentaram facilidade para citar os problemas ambientais da região da escola, predominando lixo, foco de dengue e desmatamento. Isso sugere que a experiência vivida favorece a compreensão de conceitos relacionados ao ambiente. A percepção sobre o conceito de Meio Ambiente predominante foi uma visão Socioambiental, onde o homem ou a sociedade estão inseridos, como por exemplo: "é tudo que nos rodeia e onde todos nós moramos" (figura 2). Sendo que muitos também apresentaram uma visão Ecológica/ Naturalista (conceituação ecológica; habitat, população, comunidade, ecossistema, e/ou naturalista; elementos da natureza), como por exemplo: "é um conjunto de seres vivos de diferentes espécies. Que vivem no mesmo lugar". Essa visão vem reforçar a dificuldade em diferenciar os conceitos de Meio Ambiente e Natureza manifestada nos cartazes, onde prevaleceram imagens do ambiente, de animais e vegetais, além dos problemas ambientais. Esses resultados são similares aos encontrados por Collere (2005), o qual pesquisou a percepção de Meio Ambiente de professores e encontrou as visões naturalistas e de ambiente como espaço de vida, predominantes nas respostas, seguido de interação entre sociedade e natureza. Talvez isso possa indicar a necessidade de aprofundamento teórico na área, para professores e alunos, o que seria possível através de uma educação ambiental crítica.

$\mathrm{Na}$ segunda etapa dos questionários destaca-se o surgimento da visão Abrangente, considerando uma maior integração entre os vários aspectos que este conceito engloba, em que as falas sugerem uma maior reflexão, na qual o ambiente não "gira" apenas ao redor do homem. Na visão Abrangente ainda estão inseridas falas como "É qualquer lugar independente de ser natural ou modificado pelo homem" e "Onde nós vivemos junto com a fauna e flora e com os obstáculos do dia-a-dia (...)", ou seja, mesmo que incluam aspectos naturalistas, os aspectos sociais estão integrados. Como este não é um conceito bem definido segundo os meios pelos quais os alunos utilizam para se informar, como a escola e a TV, a confusão entre natureza e meio ambiente se mantém, embora menos frequente na segunda etapa do questionário. Sato $(1997$, p.6) afirma que "a mídia tem contribuído para a formação de pré-conceitos sobre as questões relativas ao ambiente" e que tais "distorções podem ser por falta de informações adequadas, mas outras vezes, parecem ser provocadas para prejudicar a imagem dos valores ambientais".

Figura 2: Categorias de percepções dos alunos sobre o conceito de Meio Ambiente. 


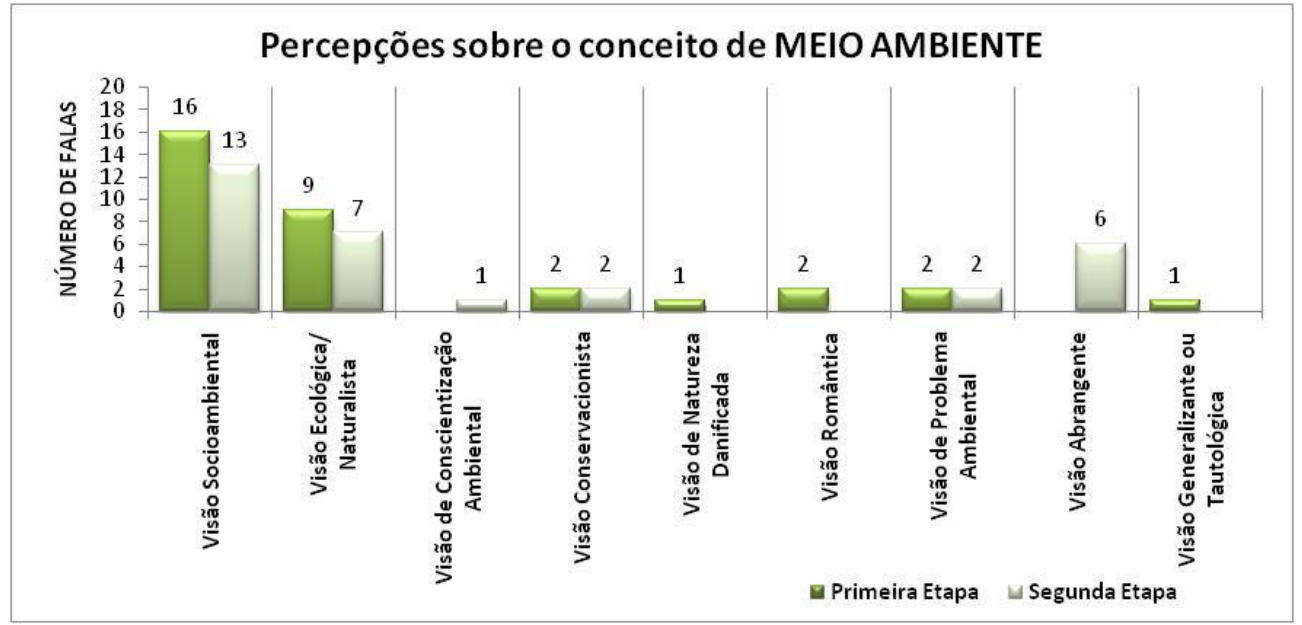

No conceito de Natureza (Figura 3) destaca-se a visão Ecológica/Naturalista (onde o homem não está inserido), em ambas as etapas do questionário, seguida da visão de Paisagem (conceituação de beleza cênica, paisagem e senso estético) na primeira etapa, e Generalizante ou Tautológica (conceituação superficial; "tudo" ou "nada", ou sem sentido) na segunda etapa. Isso também aponta a dificuldade para definir esse termo. Tamaio (2002, p.43), ao analisar o material sobre o conceito de natureza, produzido por seus alunos do $6^{\circ}$ ano do Ensino Fundamental, criou as seguintes categorias: "Romântica", "Utilitarista", "Científica", "Generalizante", "Naturalista" e "Socioambiental". Segundo ele, ao mediar, como professor, a construção do conceito de natureza, os alunos passaram de uma visão Romântica para uma visão Socioambiental, sendo que a visão de Paisagem aqui apresentada poderia ser inserida na visão Romântica de Tamaio. Isto indica como os alunos tendem a idealizar e excluir os seres humanos do conceito de natureza.

Figura 3: Categorias de percepções dos alunos sobre o conceito de Natureza.

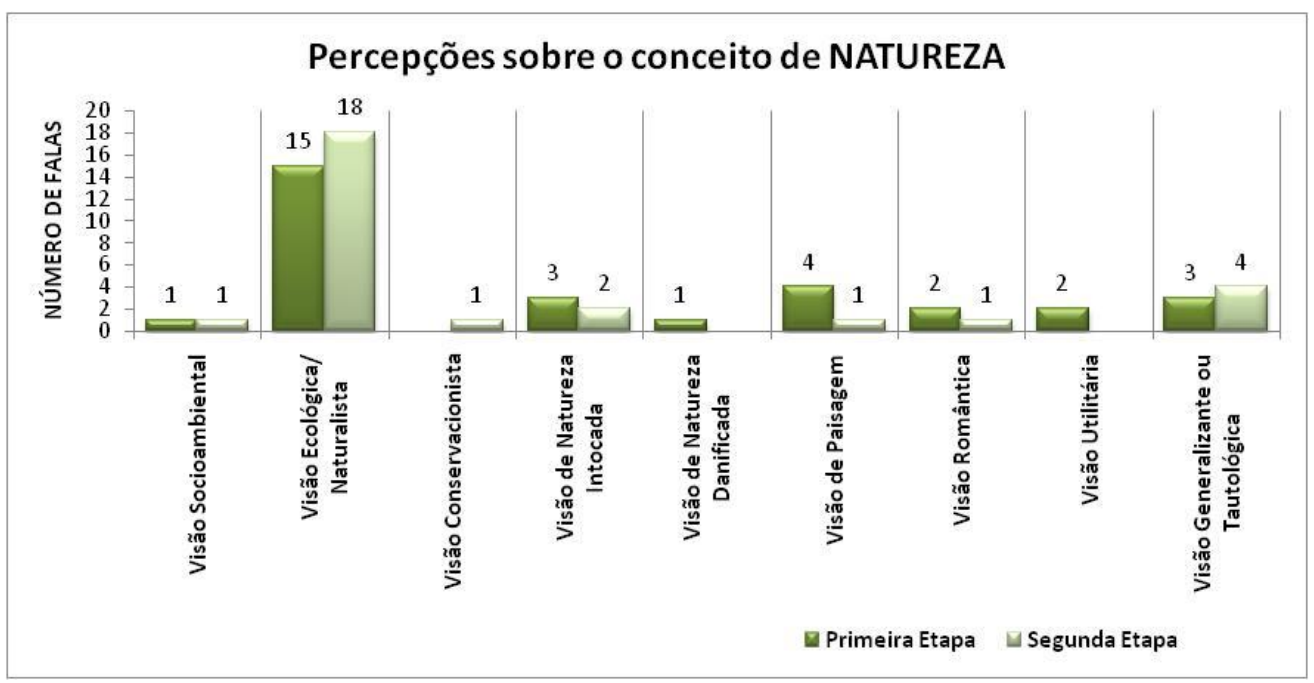

A percepção sobre o conceito de Educação Ambiental (Figura 4) se concentrou nas visões Conservacionista (conceituação de conservação, manejo do uso humano do meio) e de 
Conscientização Ambiental (conceituação de conscientização e formas de adquirir conhecimento). Isso mostra que, na falta de uma reflexão crítica sobre o tema, as informações difundidas ainda se resumem aos primórdios da EA conservacionista, ou reduzido à informação sobre o ambiente. Os professores pesquisados por Collere (2005) também apresentaram predominantemente essas visões. Na segunda etapa alguns alunos relacionaram EA às visões de Problema Ambiental e Socioambiental e um aluno apresentou uma visão Abrangente, na qual a EA é apontada como um "processo", categorias que indicam a inserção humana.

Na percepção sobre o conceito de Unidade de Conservação (Figura 5) destacou-se a visão Conservacionista na primeira e a visão Institucional na segunda etapa. Esse fato reforça a ideia de que os alunos desconheciam o que é uma UC em sua totalidade. Na segunda etapa, a visão Institucional predominante se deve à associação feita com o PESET, já que os alunos passaram a conhecer um tipo de Unidade de Conservação. Isso justifica também o dobro de categorias citadas na segunda etapa, devido ao conhecimento que passaram a ter sobre as outras funções das Unidades de Conservação, como visitação e educação.

Figura 4: Categorias de percepções dos alunos sobre o conceito de Educação Ambiental

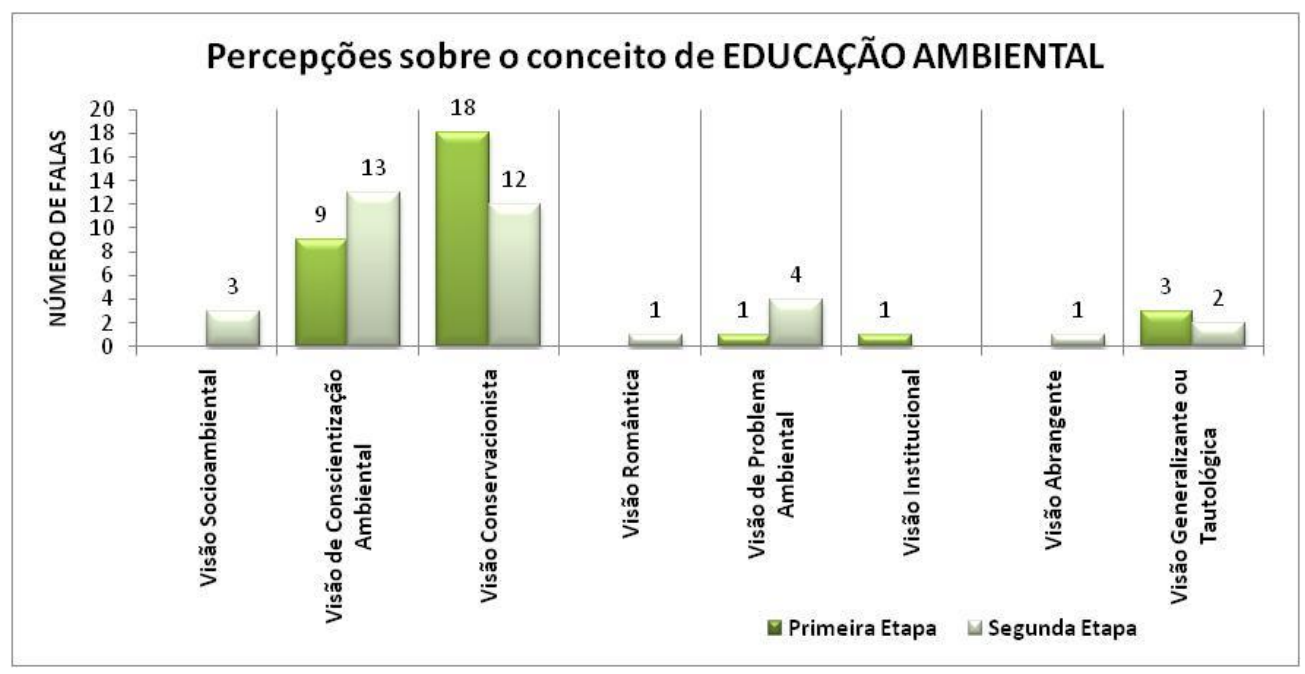

Figura 5: Categorias de percepções dos alunos sobre o conceito de Unidade de Conservação. 


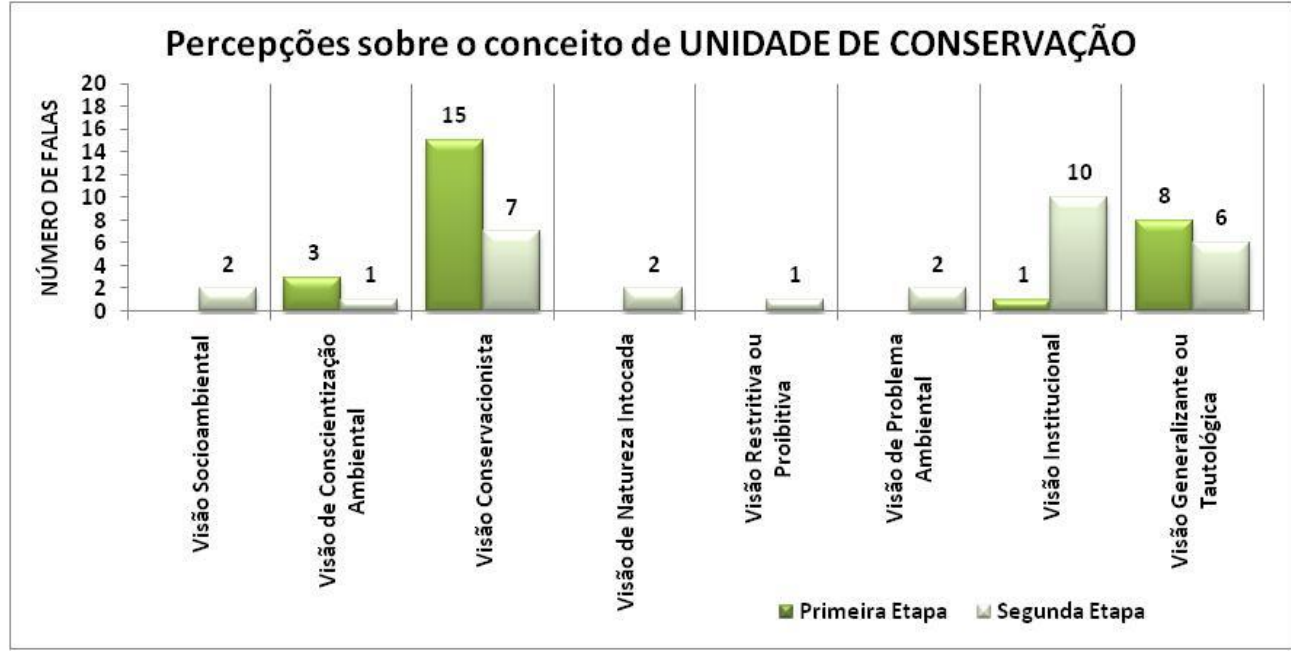

A percepção sobre o conceito de Parque Natural (Figura 6) foi de visão de Natureza Intocada (conceituação de natureza preservada, intocada, sem influência do homem) e de visão Ecológica/Naturalista, na primeira etapa, para uma visão Conservacionista na segunda etapa. A visão de Natureza Intocada desaparece na segunda etapa, provavelmente porque os alunos perceberam a inserção do ser humano nos Parques através da sua vivência. Destaca-se na segunda etapa o surgimento das visões Socioambiental, a qual insere pessoas na percepção sobre o Parque, e Abrangente, que integra vários aspectos, reforçando essa ideia, como no exemplo: "É um espaço preservado por instituições ambientais aberto ao público para visitas e explorações inspecionadas."

Figura 6: Categorias de percepções dos alunos sobre o conceito de Parque Natural.

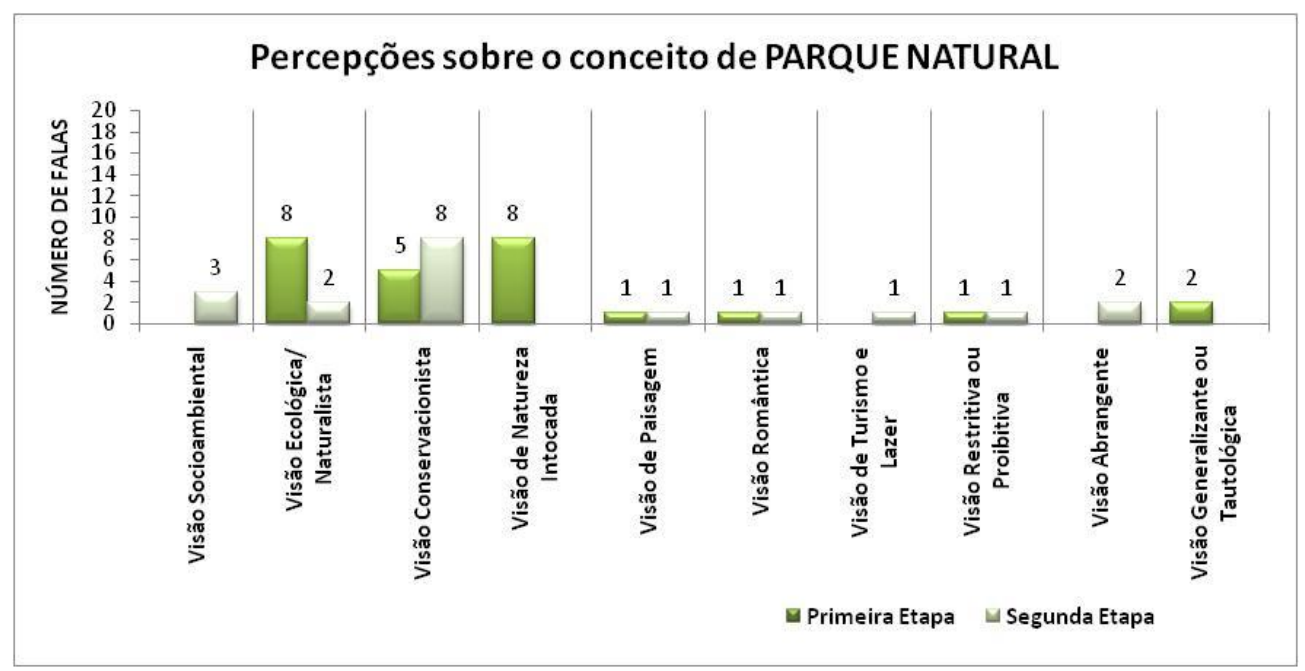


Sato (1997) lembra que "a EA deve ser desenvolvida com os objetivos de auxiliar os alunos a construírem uma consciência global das questões relativas ao meio, para que possam assumir posições afinadas com os valores referentes à vida”. Segundo BRASIL(1999, p.30):

\begin{abstract}
Para que os alunos possam compreender a complexidade ambiental, é fundamental oferecer-lhes uma visão abrangente que englobe diversas realidades, e ao mesmo tempo, uma visão contextualizada da realidade ambiental, o que inclui, além do meio biofísico, as condições sociais.
\end{abstract}

As percepções dos alunos sobre os conceitos abordados no questionário também auxiliaram no traçado das atividades. Essa ferramenta foi útil para a compreensão da sua visão prévia e não tinha a pretensão de modificar todos os pré-conceitos apresentados por eles. A desconstrução de alguns conceitos, mais do que a sua construção, foi fundamental para a participação efetiva em todas as etapas do Projeto, pois aumentou a curiosidade e envolveu os alunos como sujeitos deste processo, valorizando o potencial de cada um. O aprofundamento dos conceitos apresentados pode auxiliar no entendimento dos pontos mais complexos que envolvem a relação homem-natureza, inclusive suscitando uma participação mais ativa no que se refere à solução ou minimização dos problemas socioambientais.

\title{
CONSIDERAÇÕES FINAIS
}

O projeto foi capaz de integrar os alunos de Ensino Médio ao PESET, aliando conhecimento, reflexão, desafios, afetividade, curiosidade, imaginação e noção de pertencimento, processos necessários para alcançar os objetivos da EA. As atividades na escola e as Trilhas Interpretativas possibilitaram uma mudança de percepção dos alunos sobre o PESET, verificada pelo surgimento das visões Socioambiental e Abrangente e desaparecimento da visão de Natureza Intocada. A inserção crítica no ambiente foi possível através das Trilhas Interpretativas, principalmente pela comparação da experiência vivida nas duas visitas ao PESET. Isso foi evidenciado pelos depoimentos, os quais chamavam a atenção para as diferenças entre a Enseada do Bananal, onde não há residências, e o Morro das Andorinhas, onde há moradores e é possível avistar os aspectos sociais que envolvem o entorno do Parque.

As atividades realizadas em sala de aula, através da Pesquisa-ação, foram essenciais para o entendimento e aprofundamento das questões relacionadas ao Parque e um importante complemento para os alunos que não participaram de todas as visitas. Os produtos gerados durante as atividades desencadearam maior interesse pelas aulas, motivando-os a divulgar o projeto e, consequentemente, o Parque. O movimento dialético permitiu a valorização da participação dos alunos, pois a opinião deles foi considerada para o traçado das atividades e a escolha do produto final foi importante no processo de aprendizagem.

As escolas podem atuar nos parques mais sistematicamente, através do desenvolvimento de projetos que visem à educação e interpretação ambiental na área protegida; funções importantes para a conservação. Mesmo que a escola não apresente a disciplina "Projeto", pode-se desenvolver o tema dentro das disciplinas tradicionais, de forma transversal, e até aliar o conteúdo curricular às atividades. 
Para as Unidades de Conservação como os parques, é necessário ultrapassar suas fronteiras, pois a biodiversidade não conhece "muros" ou "territórios" e a pressão negativa no seu entorno torna urgentes ações sociais que permitam o amortecimento desses impactos.

O caminho trilhado entre escolas e parques é certamente de "mão-dupla". As escolas podem se beneficiar no processo de ensino-aprendizagem e na formação de cidadãos mais críticos e responsáveis pelo seu ambiente, e os parques podem ser reconhecidos como espaços públicos que cumprem a função Constitucional de conservação da biodiversidade, de maneira participativa e aberta a discussão com as comunidades.

\section{REFERÊNCIAS BIBLIOGRÁFICAS}

BARDIN, L. Análise de Conteúdo. Lisboa: Edições 70, 1977c. 229p.

BENSUSAN, N. Conservação da Biodiversidade em Áreas Protegidas. Rio de Janeiro: Ed. FGV, 2006. 176p.

BRASIL. Lei 9.985/2000. Institui o Sistema Nacional de Unidades de Conservação da

Natureza. SNUC. Brasília: Instituto Brasileiro do Meio Ambiente e dos Recursos Naturais Renováveis. Diretoria de Ecossistemas, 2000. 35p.

BRASIL. Lei 9.795/1999. Institui a Política Nacional de Educação Ambiental. Brasília. Presidência da República, Casa Civil. 1999. Disponível em: < http://www.planalto.gov.br/ccivil_03/leis/19795.htm >

BRASIL. Parâmetros Curriculares Nacionais: Terceiro e Quarto Ciclos do Ensino Fundamental. Temas Transversais. Brasília: MEC/ Secretaria de Educação Fundamental - SEF, 1998. 436p.

CADEI, M.; PEREIRA, J. B. M; MOURA, N. C. Educação Ambiental. In: BASTOS, Marcos; CALLADO, Cátia Henriques. (Orgs.). O Ambiente da Ilha Grande. Rio de Janeiro: Universidade do Estado do Rio de Janeiro, Centro de Estudos Ambientais e Desenvolvimento Sustentável. 2009. 562 p. il.

CASTRO, R.S.; BAETA, A.M. Autonomia Intelectual: condição necessária para o exercício da cidadania. In: LOUREIRO, C.F.B.; LAYRARGUES, P.P.; CASTRO, RS. (orgs.).

Educação Ambiental: repensando o espaço da cidadania, 3a ed., São Paulo: Cortez, 2005.

COIMBRA, A.S. Interdisciplinaridade e Educação Ambiental: Integrando seus Princípios Necessários. Revista Eletrônica do Mestrado em Educação Ambiental, v.14, jan-jun, 2005. Disponível em:

<http://www.remea.furg.br/edicoes/vol14/art09.pdf> Acesso em: abr/2008.

COLLERE, M.A.O. Educação Ambiental: a Contribuição dos Projetos Escolares nas Discussões Ambientais nas Escolas Públicas Municipais de Colombo/PR. RA'E GA, Curitiba: Editora UFPR, n. 10, p. 73-82, 2005. Disponível em: < http://ojs.c3sl.ufpr.br/ojs2/index.php/raega/article/viewFile/3393/3770> Acesso em jun/2010. 
FRANCO, M.A.S. Pedagogia da Pesquisa-ação. Educação e Pesquisa, São Paulo: v. 31, n. 003, pp.483-502, set-dez, 2005. Disponível em: <

http://redalyc.uaemex.mx/redalyc/html/298/29831311/29831311.html> Acesso em: mai/2008.

FRITZSONS, E.; MANTOVANI, L.E. A Educação Ambiental e a Conservação da Natureza.

Educação Ambiental em Ação. n.10, pp. 1 -13, set. 2004. Disponível em:

<http://www.revistaea.org/artigo.php?idartigo=237\&class=02 > Acesso em: jul/2008.

INSTITUTO ESTADUAL DO AMBIENTE (INEA). Parque Estadual da Serra da Tiririca. <http://www.inea.rj.gov.br/Portal/Agendas/BIODIVERSIDADEEAREASPROTEGIDAS/Uni dadesdeConservacao/INEA_008600\#/Sobreoparque>. Acesso em junho/2019.

PIMENTEL, D.S.; MAGRO, T.C.; SILVA FILHO. Imagens da Conservação: Em busca do apoio público para a gestão de unidades de conservação. Teoria \& Sociedade. v.19, n.2, 2011. P. 144-168.

PIMENTEL, D.S.; MAGRO, T. Múltiplos olhares, muitas imagens: o manejo de parques com base na complexidade social. GEOgraphia, América do Norte, 13 de junho. 2012a.

PIMENTEL, D.S.; MAGRO, T.C. Diferentes Dimensões da Educação Ambiental para a Inserção Social dos Parques. Revista Brasileira de Educação Ambiental. v.7, n.2, 2012b. p.4450 .

PIMENTEL, D.S.; BARCELLOS, M.M.; MEIRELES, C.P., LAMONICA, M.de O.;

PERDOMO, V.S. Trilhas Interpretativas como Estratégias de Educação Ambiental em Unidades de Conservação. In: Da Célula ao Ambiente: Propostas para o Ensino de Ciências e Biologia. Organizadores: Ricardo Tadeu Santori, Marcelo Guerra Santos e Maria Cristina Ferreira dos Santos. - Rio de Janeiro: UERJ/FFP. 2017. 240 p. il.

PRIMACK, R.B.; RODRIGUES, E. (Ed.). Biologia da Conservação. Londrina: Edição dos Editores, 2001. 327p.

SATO, M. Educação para o Ambiente Amazônico. 1997. 245p. il. Tese (Doutorado) Centro de Ciências Biológicas e da Saúde, Universidade de Federal de São Carlos, São Carlos, 1997.

SELLES, S.E.; ABREU, M. Darwin na Serra da Tiririca: Caminhos Entrecruzados entre Biologia e História. Revista Brasileira de Educação, São Paulo, n.20, p.5-22, mai./jun./jul./ago. 2002. Disponível em: <http://redalyc.uaemex.mx/src/inicio/ArtPdfRed.jsp?iCve=27502002> Acesso em: dez/ 2005.

SILVA, N.P.S.; NETO, A.R.C. A Educação Ambiental como Instrumento de Sensibilização Turística em Unidades de Conservação. Revista Eletrônica Aboré, publicação da Escola Superior de Artes e Turismo, ed. 03, 2007. Disponível em: < http://www.revistas.uea.edu.br/old/abore/comunicacao/comunicacao_pesq_3/Nathalin\%20Pri scila\%20de\%20Souza\%20da\%20Silva.pdf> Acesso em: jul/2010.

SOARES, A.M.D.; OLIVEIRA, L.M.T.; PORTILHO, E.S.; CORDEIRO, L.C.;

CAVALCANTE, D.K. Educação Ambiental: Construindo Metodologias e Práticas Participativas. In: II Encontro Associação Nacional de Pós-Graduação e Pesquisa em Ambiente e Sociedade (ANNPAS). Anais eletrônicos. Indaiatuba, 2004. Disponível em: <http://www.anppas.org.br/encontro_anual/encontro2/GT/GT10/ana_maria_dantas.pdf $>$ Acesso em: jul/2010.

TAMAIO, I. O professor na construção do conceito de natureza: uma experiência de educação ambiental. - São Paulo: Annablumme: WWF, 2002. 158p. 
TELLES, M.Q.; ROCHA, M.B.; PEDROSO, M.L.; MACHADO, S.M.C. Vivências Integradas com o Meio Ambiente. Práticas de Educação Ambiental para Escolas, Parques, Praças e Zoológicos. - São Paulo : Sá Editora, 2002. 145p.

TILDEN, F. Interpreting our heritage. 3 rd. ed. Chapel Hill: University of North Carolina press, 1977, $138 \mathrm{p}$.

TRIVIÑOS, A.N.S. Introdução à Pesquisa em Ciências Sociais: a Pesquisa Qualitativa em Educação. São Paulo: Ed. Atlas, 1987. 176 p.

VASCONCELLOS, J.M. de O. Educação e Interpretação Ambiental em Unidades de Conservação. Paraná: Ed. Fundação O Boticário de Proteção à Natureza. Cadernos de Conservação, ano 03, n.04, 2006. 86 p. 